\title{
Is Environmental Awareness a Good Predictor of an Individual's Altruism Level?
}

\author{
Kentaka Aruga 1 \\ Graduate School of Humanities and Social Sciences, Saitama University, Sakura-ku, Saitama 338-8570, Japan; \\ aruga@mail.saitama-u.ac.jp; Tel.: +81-48-858-3336
}

Received: 3 September 2020; Accepted: 23 September 2020; Published: 24 September 2020

check for updates

\begin{abstract}
This study investigated the validity of using a Likert-type environmental awareness index to predict an individual's altruism level by comparing models identifying how respondents' demographical characteristics (age, income, education, gender, etc.), degree of political and social awareness, and attitudes toward donation influence the environmental awareness index and the self-report altruism scale (SRAS). Using survey data from a sample of Japanese respondents, the study revealed a bidirectional relationship between environmental awareness and SRAS indices. Furthermore, through examining the effects of respondents' demographical characteristics and other characteristics on the environmental awareness and SRAS indices, the study identifies that the directions of the influences of these covariates on the indices were all similar when their estimated coefficients were statistically significant. Hence, the study reveals that the environmental awareness index does capture the characteristics of the SRAS index.
\end{abstract}

Keywords: global environmental awareness; local environmental awareness; self-report altruism scale; ordered probit model

\section{Introduction}

Global environmental issues, especially climate change and rainforest destruction, are wreaking havoc on the natural environment. It is suggested that such environmental degradation and ecological collapse are caused by increased economic activities [1]. To reduce anthropogenic pressure on the environment, every individual must recognize how their economic activities impact the environment and to consider living in an environmentally friendly way.

Studies suggest that people who are more concerned or aware of environmental issues are more likely to reduce their effects on the environment [2-4]. Thus, an individual's environmental awareness is an important factor in shifting people toward less environmentally damaging economic activities. Enhancing levels of environmental awareness will contribute to mitigating the effects of human activities on the environment. Therefore, it is becoming increasingly crucial to identify the factors that increase environmental awareness.

Recently, studies have revealed that altruism or altruistic motivation has a significant effect on increasing the individual's environmental awareness level when a simple Likert scale is used to measure environmental awareness [5-7]. Furthermore, many studies use Likert-type scales to evaluate an individual's environmental awareness level [8-10], but these studies do not test or mention whether a simple Likert-type environmental awareness index can capture altruism as measured by a psychometric altruism index: an index used in psychology to identify an individual's altruism level through compounding various items reflecting an individual's altruistic actions. To date, no studies have quantitatively analyzed how the Likert-type environmental awareness index is related to altruism measured with a psychometric index or how the environmental awareness index can capture factors that are linked to the psychometric altruism index. 
Hence, the objective of this study is to determine how suitable the Likert-type environmental awareness index is for predicting an individual's altruism level. The study expects that if the environmental awareness index has a bidirectional relationship with the altruism index and is affected similarly from attributes (demographical characteristics, degree of political and social awareness, attitudes toward donation) that have potential impacts on the altruism index, the environmental awareness index can become a predictor for the altruism index.

The data used herein are based on a survey performed on Japanese respondents in 2018. The reason for using Japanese respondents is because according to the U.S. News' 2020 Best Countries for Green Living [11], among the countries with the top five economies in the world, Japan is the only country that is also ranked within the top five countries for green living. It is known that people from richer nations are more likely to have higher environmental awareness levels than people from poorer nations [12]. Japan is a country with high levels of green living as well as a high GDP, and hence, using data from a sample of Japanese respondents is suitable for measuring an individual's environmental awareness level.

There are several reasons why it is essential to conduct a study to validate the use of the Likert-type environmental awareness index for predicting an individual's altruism level. First, people who are concerned about environmental issues are not necessarily altruistic; some people worry about environmental problems on behalf of themselves. It could be that these people care about environmental issues only to prevent their quality of life from deteriorating. It could be that they are not worried about the people in future generations or the suffering of other people from environmental degradation but are simply anxious about the environmental problems they might face, such as the pollution of their drinking water and forest fires in their vicinity. Second, there could be a gap between high environmental awareness and actual environmental attitudes or actions. For example, people with high knowledge of environmental issues do not necessarily drive less, use less electricity to reduce their environmental footprint, or participate in environmental activities. Thus, to use the environmental awareness indices to predict an individual's altruism level, we need to verify whether such indices truly reflect an individual's altruism level. Third, if it becomes apparent that a simple Likert-type environmental awareness index can be used to predict an individual's altruism level, we can reduce the efforts to create a special and complex environmental awareness index for measuring an individual's altruism level. There is no generally accepted definition for environmental awareness, and the way environmental awareness is measured often varies among different disciplines [13]. Hence, if our study reveals that a simple Likert-type environmental awareness index is sufficient for predicting an individual's altruism level, it will help researchers to reduce the time and effort they would spend developing new indices for examining the relationship between altruism and environmental awareness.

Studies measuring altruism often use either a self-reported type or a dictator game experiment, but this study applies the self-report altruism scale (SRAS) developed by Rushton et al. [14]. The first reason for using this SRAS index for measuring altruism is because since the Likert-type environmental awareness index is obtained from self-reported answers of the survey respondents, it is reasonable to use an altruism index that is gathered in a self-reported way as to compare with the environmental awareness index. The second reason for using the SRAS in this study is because the dictator game model often fails to measure altruism due to experimental demand effects [15] while the psychometric SRAS index is more broadly applied in various fields for measuring individual's altruism levels [16-19]. The third reason is that the SRAS index is based on not one type of altruistic action but is a composite of actual altruistic actions taken by the individuals. Hence, this index reflects the actual altruistic behavior taken rather than measuring an individual's awareness of altruism.

Although there are various definitions of altruism [20], this study defines altruism as one's action that benefits others without expecting some kind of external reward. The SRAS is an index that at least captures such altruistic action while environmental awareness is only an individual's awareness that is often assumed to be related to altruism because people with high environmental awareness are more likely to be prosocial, and prosocial individuals tend to take altruistic action. By investigating 
the connection between environmental awareness and SRAS indices, the current study contributes to verifying whether an individual's altruistic awareness is linked with his or her altruistic action.

In the next section, we introduce the methods of the study. The third section describes the results of the study. Finally, the last section includes the conclusion of the study.

\section{Methods}

In this section, we first describe the econometric models used to identify the use of the Likert-type environmental awareness index for predicting altruism by comparing models with the environmental awareness index and the SRAS as dependent variables. Second, we explain the details of the survey that was administered to obtain the data used in the econometric models.

\subsection{Econometric Model}

Our analyses are performed using the ordered probit model. Denoting $Y_{i}$ as our observed ordinal dependent variable and $J$ as the highest rank order such that $Y_{i} \in\{1, \ldots, J\}, Y_{i}$ is determined by an unobserved latent variable $Y^{*}$ :

$$
Y_{i}=J \text { iff } \kappa_{j-1} \leq \Upsilon^{*}<\kappa_{j} j=1, \ldots, J
$$

where $\kappa_{0}, \ldots, \kappa_{J}$ are the threshold parameters such that $\kappa_{0}=-\infty$ and $\kappa_{J}=+\infty$. Then, the probit model can be expressed as:

$$
Y^{*}=X_{i}^{\prime} \beta+u_{i}, u_{i} \sim N(0,1)
$$

where $X_{i}$ and $\beta$ are $k \times 1$ vectors of observed explanatory variables and unknown parameters, and $u_{i}$ is the random error term. The probability of observing a particular ordinal outcome for a given $X_{i}$ is:

$$
P\left(Y_{i}=j \mid X_{i}\right)=F\left(\kappa_{j}-X_{i}^{\prime} \beta\right)-F\left(\kappa_{j-1}-X_{i}^{\prime} \beta\right),
$$

where $F$ represents the cumulative distribution function of the standard normal distribution.

The $\beta$ s are estimated by the log-likelihood function written as:

$$
\ln L=\sum_{i=1}^{n} \sum_{j=1}^{J} Z_{i j} \ln P\left(Y_{i}=j \mid X_{i}\right)
$$

where $Z_{i j}$ is an indicator variable that equals 1 when $Y_{i}=j$ and equals 0 otherwise.

Using the above ordered probit model, we estimated a model where $Y_{i}$ represents the SRAS and two models where $Y_{i}$ represents the Likert-type environmental awareness indices:

$$
\begin{aligned}
& \text { SRAS }=\beta_{1} \text { global env. }+\beta_{2} \text { local env. }+\sum_{i=3}^{10} \beta_{i} X_{i}, \\
& \text { global env. }=\beta_{1} S R A S+\beta_{2} \text { local env. }+\sum_{i=3}^{10} \beta_{i} X_{i}, \\
& \text { local env. }=\beta_{1} \text { SRAS }+\beta_{2} \text { global env. }+\sum_{i=3}^{10} \beta_{i} X_{i} .
\end{aligned}
$$

We identify if the environmental awareness and SRAS indices have a bidirectional relationship and test if variables such as demographical characteristics (age, income, education, gender, etc.), degree of political and social awareness, and attitudes toward donation that are likely to have impacts on the SRAS have the same effects on the environmental awareness indices. For these purposes, 
all the independent variables included in Equations (5)-(7) are the same except for the SRAS and the environmental awareness indices.

Table 1 shows the descriptions of the variables included in the equations. As seen in the table, the SRAS refers to the self-report altruism scale that was developed based on Rushton et al. [14]. To compare this scale with the Likert-type environmental awareness index, we converted the average SRAS score to an ordinal variable, as described in the table. The details of the items on the SRAS are presented in Table 2. We administered the SRAS to Japanese respondents, but the original questionnaire created by Rushton et al. [14] was used for Canadian respondents. Thus, in this study, some of the items included in the original index were modified to fit Japanese people. In this process, we included questionnaire items 12, 15, and 21 of Oda et al. [21], which developed the Japanese version of SRAS.

Table 1. Variable description.

\begin{tabular}{|c|c|c|c|}
\hline Variable & Description & Mean & Std. Dev. \\
\hline SRAS & $\begin{array}{c}\text { An average score of the self-report altruism } \\
\text { scale: } 1=1 \leq \text { SRAS }<1.5,2=1.5 \leq \text { SRAS }< \\
2.5,3=2.5 \leq \text { SRAS }<3.5,4=3.5 \leq \text { SRAS }< \\
4.5, \text { and } 5=4.5 \leq \text { SRAS. }\end{array}$ & 2.86 & 0.83 \\
\hline global env. & $\begin{array}{c}\text { Degree of interest in global environmental } \\
\text { problems, such as deforestation of rainforests: } \\
1=\text { have no interest at all to } 5 \text { = have a strong } \\
\text { interest. }\end{array}$ & 3.44 & 0.95 \\
\hline local env. & $\begin{array}{c}\text { Degree of interest in local environmental } \\
\text { problems, such as contamination of local } \\
\text { drinking water: } 1 \text { = have no interest at all to } 5 \\
=\text { have a strong interest. }\end{array}$ & 3.54 & 0.92 \\
\hline age & $\begin{aligned} 1=20-29,2= & 30-39,3=40-49,4=50-59 \\
& \text { and } 5=60-69 .\end{aligned}$ & 3.12 & 1.38 \\
\hline edu & $\begin{array}{c}1=\text { Graduated junior high school, } 2= \\
\text { Graduated high school, } 3=\text { Graduated junior } \\
\text { college, } 4=\text { Did not finish undergraduate, } 5= \\
\text { Earned a bachelor's degree, and } 6=\text { Earned a } \\
\text { graduate degree. }\end{array}$ & 4.03 & 1.38 \\
\hline income & $\begin{array}{c}1=\text { Less than } 2 \text { million yen, } 2=2-4 \text { million } \\
\text { yen, } 3=4-6 \text { million yen, } 4=6-8 \text { million yen, } \\
5=8-10 \text { million yen, } 6=10-12 \text { million yen, } \\
\text { and } 7 \text { = More than } 12 \text { million yen. }\end{array}$ & 2.60 & 1.63 \\
\hline male & $1=$ male, and $0=$ female & 0.50 & 0.50 \\
\hline child & $\begin{array}{c}1=\text { Have experience in raising children, and } 0 \\
=\text { No experience in raising children. }\end{array}$ & 0.51 & 0.50 \\
\hline social interest & $\begin{array}{l}\text { Degree of interest in political and social } \\
\text { issues: } 1=\text { have no interest at all to } 5=\text { have a } \\
\text { strong interest. }\end{array}$ & 3.59 & 0.97 \\
\hline pure donation & $\begin{array}{l}\text { Willing to donate to a region without } \\
\text { receiving a gift from the region: } 1=\text { yes, and } \\
\qquad 0=\text { no. }\end{array}$ & 0.54 & 0.50 \\
\hline gifted donation & $\begin{array}{l}\text { Willing to donate to a region if a gift is } \\
\text { provided as a return from the region: } 1=\text { yes, } \\
\text { and } 0=\text { no. }\end{array}$ & 0.32 & 0.47 \\
\hline
\end{tabular}


Table 2. Items on the self-report altruism scale (SRAS).

\begin{tabular}{|c|c|c|}
\hline \multicolumn{2}{|r|}{ The Frequency (1 (Never) to 5 (Very Often)) of Carrying Out the Following Acts: } & \multirow{2}{*}{$\begin{array}{l}\text { Variable Name } \\
\text { Street }\end{array}$} \\
\hline 1 & You have told a stranger the way to a destination when asked by him or her. & \\
\hline 2 & You have donated money to charity. & Charity \\
\hline 3 & $\begin{array}{l}\text { You have helped open and close an elevator door for a stranger when you were } \\
\text { near the door. }\end{array}$ & Elevator \\
\hline 4 & $\begin{array}{l}\text { You have corrected the right price when a salesperson mistakenly charged a } \\
\text { cheaper amount. }\end{array}$ & Change \\
\hline 5 & You have lent something to a stranger when asked by him or her. & Lend \\
\hline 6 & $\begin{array}{l}\text { You have provided information to a stranger (for example, how to buy a ticket) } \\
\text { or knowledge (this could be either face to face or via the internet) to help him or } \\
\text { her. }\end{array}$ & Information \\
\hline 7 & You have participated in volunteer activities. & Volunteer \\
\hline 8 & You have helped a disabled or elderly stranger to cross streets. & Disabled \\
\hline 9 & You have given up your seat on a train or a bus to a disabled or elderly stranger. & Seat \\
\hline 10 & You have picked up a stranger's bicycle when it was laid down on the ground. & Bicycle \\
\hline
\end{tabular}

The average of the SRAS was calculated based on the respondents' pick regarding the questions presented in Table 2. Then, since the environmental awareness indices are ordinal variables, the average SRAS was converted to a similar ordinal variable as shown in Table 1. As seen in Table 1, most of the variables are ordinal variables except male, child, pure donation, and gifted donation being dummy variables.

To test the reliability of our modified SRAS, we estimated Cronbach's $\alpha$, Revell's $\beta$, and McDonald's $\omega_{h}$ [22] using the items shown in Table 2. Most studies testing the reliability of an index only use Cronbach's $\alpha$, but Zinbarg et al. [22] suggest that Cronbach's $\alpha$ can result in overestimation of the scale, and thus, it is important to use several indices to determine the validity of the scale. Knight et al. [23] suggest that the acceptable thresholds for the $\alpha, \beta$, and $\omega_{h}$ coefficients are above $0.8,0.7$, and 0.6, respectively, and thus, these values are used as the cutoff criteria herein.

Tables 3 and 4 show the results of the reliability analyses. It is apparent from Table 3 that all the raw $\alpha$ values of the items included in the SRAS were below the overall Cronbach's $\alpha$ coefficient shown in Table 4. This suggests that deleting any of the items in Table 2 will not improve the overall reliability of the scale. Furthermore, the estimated $\alpha, \beta$, and $\omega_{h}$ coefficients shown in Table 4 are all above the cutoff criteria, indicating that the SRAS items used in this study (see Table 2) are statistically valid.

Table 3. Cronbach's alpha coefficient if an item is deleted.

\begin{tabular}{cccc}
\hline & Raw $\boldsymbol{\alpha}$ & Std. $\boldsymbol{\alpha}$ & Avg. Interitem Corr. \\
\hline Street & 0.85 & 0.85 & 0.38 \\
Charity & 0.85 & 0.85 & 0.39 \\
Elevator & 0.85 & 0.86 & 0.4 \\
Change & 0.85 & 0.85 & 0.38 \\
Lend & 0.85 & 0.85 & 0.39 \\
Information & 0.84 & 0.85 & 0.38 \\
Volunteer & 0.85 & 0.85 & 0.39 \\
Disabled & 0.84 & 0.84 & 0.38 \\
Seat & 0.84 & 0.84 & 0.37 \\
Bicycle & 0.85 & 0.85 & 0.38 \\
\hline
\end{tabular}

Next, we explain the details of the environmental awareness indices used in the study (see Table 1). Many studies measuring an individual's environmental awareness level use a Likert-type scale $[5,10,24]$. 
Thus, this study also asked the survey respondents about their interests in environmental issues using this type of scale. In this study, the environmental awareness indices are ranked on a five-point scale ( $1=$ "have no interest at all" to $5=$ "have a strong interest"). It is known that an individual's attitude regarding environmental policy differs depending on whether the environmental issue described in the survey is about global or local environmental problems [25]. Thus, in this study, we obtained data for an individual's environmental awareness level toward both global and local environmental problems. Equation (5) captures how global and local environmental awareness influence the SRAS, Equation (6) examines the effects of the SRAS on the global environmental awareness index, and Equation (7) identifies the relationship between the local environmental awareness index and the SRAS. Using Equations (5)-(7), the magnitude of the effects between the SRAS and the environmental awareness indices are investigated by estimating the average marginal effects of the changes in these indices.

Table 4. Reliability coefficients.

\begin{tabular}{cc}
\hline Test Types & Coefficient \\
\hline Cronbach's $\alpha$ & 0.86 \\
Revell's $\beta$ & 0.78 \\
McDonald's $\omega_{h}$ & 0.67 \\
\hline
\end{tabular}

To determine the appropriateness of using environmental awareness indices for predicting an individual's altruism level, we tested the effects of demographic variables (age, educational achievement, income levels, gender, having children), the degree of political and social awareness, and attitudes toward donation on the environmental awareness indices and the SRAS. This was done by comparing the estimation results of the models presented in Equations (5)-(7). The variables to examine their effects on the environmental awareness indices and the SRAS are included as $\sum_{i=3}^{10} \beta_{i} X_{i}$ in Equations (5)-(7). The multicollinearity among all the independent variables was assessed by the variance inflation factor (VIF). The VIF ranged between 1.20 and 2.52, suggesting that all the models of this study have low multicollinearity among the covariates.

The reason for including the demographic variables is because previous studies suggest that these variables are likely to influence an individual's altruistic behavior. For example, Chou [26] finds that age has a positive effect on altruism, Westlake et al. [27] reveal that educational achievement has a positive impact on altruism, and Hoffman [28] suggests that altruism increases with income. Furthermore, Piper and Schnepf [29] and Branas-Garaza et al. [30] indicate that women are more altruistic than men. Although the effects of having children on altruism vary under different circumstances, the issue has long been discussed in the context of parental altruism [31-33].

The social interest variable considers how an individual's degree of political and social awareness is related to altruism and environmental awareness levels. This variable is included in our models since previous studies suggest that altruism and environmental awareness are strongly related to prosocial behavior and political orientation [34-37].

Finally, we included pure donation and gifted donation (see Table 1) in the models to consider the effects of donation attitudes on individuals' altruism and environmental awareness levels. Japan is ranked as one of the lowest developed nations in the World Giving Index [38], and Japanese citizens are known to be less active and generous with respect to donation. However, more Japanese people are becoming interested in donation due to the program called the Furusato Nozei (hometown tax donation system), which was launched in 2008 [39]. However, the Furusato Nozei program is a donation system based on reciprocal gifts. Whenever the donors donate to the municipal governments, these local governments send back special gifts to the donors in exchange for the money donated. Hence, the type of donation popular in Japan is not a donation in a pure sense, and when administering a survey on Japanese respondents to assess their donation attitudes, it is important to separate whether they are 
willing to donate with or without receiving gifts in return. Variables to assess both pure donation and gifted donation are included in the models to control for these effects.

\subsection{The Survey}

The survey to assess individuals' environmental awareness and altruism levels was administered with support from the Japanese online research company Nikkei Research Inc. Since the survey was performed across all parts of Japan, a quota sampling method was used by balancing the regional population distribution, age, and gender according to the 2015 Japanese population census. The survey was conducted between 26 October and 31 October 2018. A total of 2546 respondents participated in the survey. We presented a consent form at the beginning of the survey and only respondents who agreed to participate in the survey answered the questionnaire. We also allowed them not to answer questions that they feel uncomfortable with. Thus, some of the respondents refused to provide their demographic information and the actual number of respondents included in the model estimation is 2539. Table 5 depicts a summary of the demographic variables of our sample respondents. The sample distribution of age and gender presented in the table is very similar to the 2017 Japanese population census [40].

Table 5. Summary of the demographic variables of the sample respondents.

\begin{tabular}{|c|c|c|c|}
\hline & Variables & Freq. & Percentage \\
\hline \multirow{5}{*}{ Age } & $20-29$ & 406 & 15.93 \\
\hline & $30-39$ & 499 & 19.58 \\
\hline & $40-49$ & 582 & 22.83 \\
\hline & $50-59$ & 488 & 19.14 \\
\hline & $60-69$ & 571 & 22.40 \\
\hline \multirow{6}{*}{ Education } & Graduated junior high school & 17 & 0.67 \\
\hline & Graduate high school & 511 & 20.07 \\
\hline & Earned a bachelor's degree & 519 & 20.38 \\
\hline & Graduated Jr. college & 46 & 1.81 \\
\hline & Unfinished undergraduate & 1237 & 48.59 \\
\hline & Earned a graduate degree & 216 & 8.48 \\
\hline \multirow{7}{*}{ Income } & Below 2 million yen & 840 & 33.08 \\
\hline & 2-4 million yen & 583 & 22.96 \\
\hline & 4-6 million yen & 490 & 19.30 \\
\hline & 6-8 million yen & 289 & 11.38 \\
\hline & 8-10 million yen & 152 & 5.99 \\
\hline & 10-12 million yen & 87 & 3.43 \\
\hline & Above 12 million yen & 98 & 3.86 \\
\hline \multirow{2}{*}{ Male } & Male & 1282 & 50.29 \\
\hline & Female & 1267 & 49.71 \\
\hline \multirow{2}{*}{ Child } & Have children experience & 1292 & 50.69 \\
\hline & Have no children experience & 1257 & 49.31 \\
\hline
\end{tabular}

Like any other survey, questions related to environmental awareness and SRAS indices are likely affected by the social desirability bias. However, it is suggested that anonymous, self-administered surveys contain fewer desirability biases than telephone and face-to-face surveys [41]. Hence, as the current study conducted a self-administered online survey, I believe such social desirability bias was controlled to a minimum compared to telephone and face-to-face surveys.

\section{Results and Discussion}

Table 6 shows the results of the ordered probit estimation of the three models: the SRAS model, the global environment model, and the local environment model. Regarding the bidirectional relationships among SRAS, global environmental awareness, and local environmental awareness, 
the results reveal that all the variables have a positive effect on each other. This indicates that an individual with a higher altruism level tends to be more concerned about both the global and local environment, and one who cares about global and local environmental issues has a higher altruism level. The results indicate that regardless of whether an individual's environmental awareness is global or local, anyone who is pro-environmental to some extent is inclined to be more altruistic.

Table 6. Ordered probit estimation.

\begin{tabular}{|c|c|c|c|c|c|c|c|c|c|}
\hline & \multicolumn{3}{|c|}{ SRAS } & \multicolumn{3}{|c|}{ Global Environment } & \multicolumn{3}{|c|}{ Local Environment } \\
\hline SRAS & na & na & na & $0.086^{* * *}$ & 0.030 & 2.83 & $0.118^{* * *}$ & 0.031 & 3.85 \\
\hline local env. & $0.135^{* * *}$ & 0.036 & 3.75 & $1.202^{* * *}$ & 0.034 & 35.84 & na & na & na \\
\hline age & -0.002 & 0.018 & -0.13 & $0.073^{* * *}$ & 0.019 & 3.83 & -0.012 & 0.019 & -0.61 \\
\hline edu & $0.050^{* * *}$ & 0.017 & 2.96 & 0.005 & 0.018 & 0.29 & $0.054^{* * *}$ & 0.018 & 3.00 \\
\hline male & $-0.186^{* * *}$ & 0.047 & -3.98 & $-0.175^{* * *}$ & 0.050 & -3.53 & $-0.100 * *$ & 0.050 & -2.01 \\
\hline child & $0.199 * * *$ & 0.048 & 4.13 & -0.026 & 0.051 & -0.51 & -0.007 & 0.051 & -0.14 \\
\hline social interest & $0.167^{* * *}$ & 0.026 & 6.43 & $0.280^{* * *}$ & 0.027 & 10.24 & $0.161^{* * *}$ & 0.027 & 5.87 \\
\hline pure donation & $0.611^{* * *}$ & 0.069 & 8.90 & 0.114 & 0.073 & 1.57 & $0.210^{* * *}$ & 0.073 & 3.01 \\
\hline gifted donation & $0.291^{* * *}$ & 0.071 & 4.09 & -0.035 & 0.075 & -0.46 & 0.107 & 0.075 & 1.42 \\
\hline
\end{tabular}

Comparing the effects of the demographic variables on the three indices, all the statistically significant variables had the same impact on the indices. Education had a positive and significant effect on the SRAS and local environmental awareness models. This indicates that individuals with higher levels of education are more likely to be altruistic and more conscious of local environmental issues. Moreover, in all three models, the male gender had a negative and significant effect, indicating that women are more altruistic and pro-environmental than men. These results are consistent with previous studies suggesting that education has a positive effect on altruism [27] and that females tend to be more altruistic than males $[29,30]$.

The effects of other factors on the three indices also had the same effects on the three indices when they were significant. The social interest variable had a positive and significant effect in all three models, indicating that people who are interested in political and social issues are more altruistic and pro-environmental than those who are indifferent about such issues. The pure donation also had a positive impact on the SRAS and local environmental awareness models, showing that those who are willing to provide a donation without any reciprocation are more altruistic and pro-environmental if the environmental issue is a local issue.

Regarding the direction of the effects of these factors on the three indices, the results of Table 6 indicate that all three models are quite similar, but the SRAS and local environment models are more similar among the three. This might be because, as shown in Table 2, the SRAS is measured based on the respondents' actual activities, but the items included in the scale mostly describe behaviors that occur in the respondents' local area; thus, this locality might have led the index to be more similar to the local environmental awareness variable.

Finally, since the raw coefficients in Table 6 do not indicate the magnitude of the effects in ordered probit models, the average marginal effects among the SRAS and the global and local environmental awareness indices were calculated. Figure 1 shows the results. It is apparent from the figure that when the rank orders of the indices chosen by the respondents are above 3, all the marginal effects become positive, indicating that when people have higher SRAS or environmental awareness scores, their marginal effects on other indices turn positive. The figure also shows that environmental awareness indices have larger marginal impacts on other indices. 


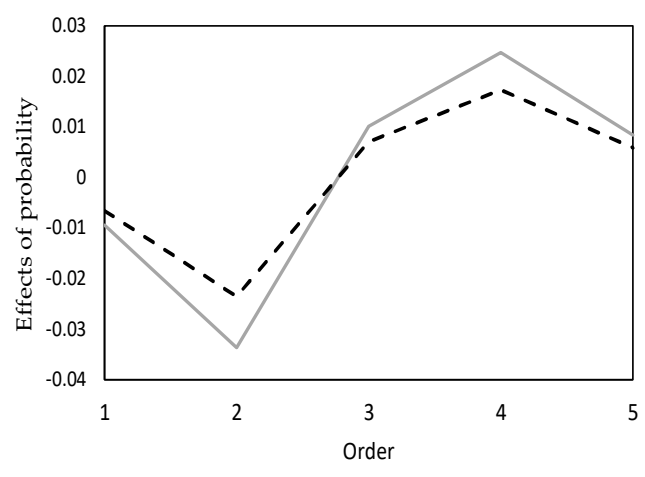

Local env. - - - global env.

(a)

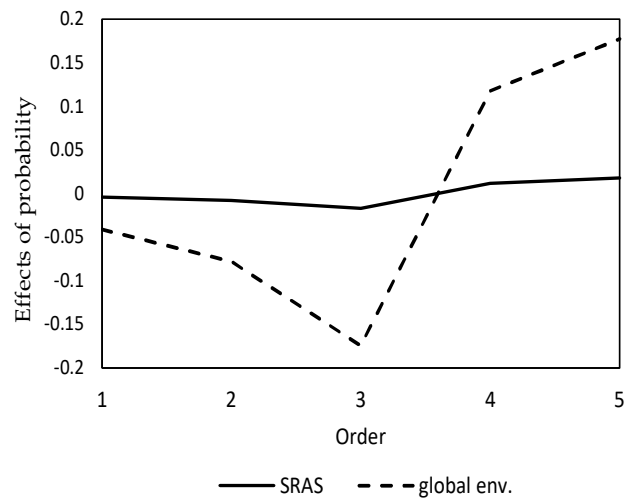

(c)

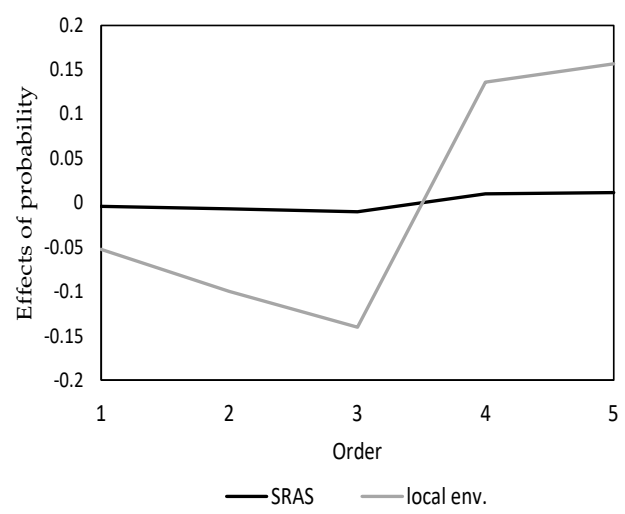

(b)

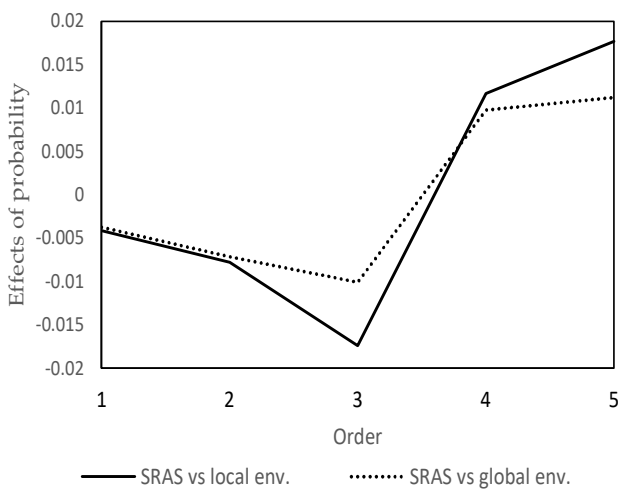

(d)

Figure 1. Average marginal effects on the SRAS and global and local environmental awareness. (a) Average marginal effects on SRAS; (b) Average marginal effects on global env; (c) Average marginal effects on local env; (d) Average marginal effects of SRAS on environmental awareness indices.

Moreover, when the marginal effects of global and local awareness indices on the SRAS are contrasted, it is discernible that the local environmental awareness index has a higher marginal effect on the SRAS than the global environmental awareness index. This suggests that in terms of increasing the SRAS score, the local environmental awareness index has a higher impact than the global environmental awareness index. Similarly, comparing the average marginal effects of the SRAS on the environmental awareness indices, the figure indicates that when the effects are positive, the SRAS has a larger impact on the local environmental awareness index than on the global environmental awareness index. The results imply that the bidirectional relationship between the SRAS and environmental awareness is stronger when the environmental issue is a local problem. As mentioned above, this finding may be due to the SRAS items being related to behaviors in the respondent's local area. This suggests that the conventional items on the SRAS may not be sufficient for capturing global altruism, i.e., altruism that goes beyond helping local people in the respondent's everyday life. To overcome this issue, the items on the SRAS need to be modified to assess altruism related to helping people outside the respondent's community. 


\section{Conclusions}

The validity of using a Likert-type environmental awareness index to predict an individual's altruism level was assessed by comparing the environmental awareness and SRAS indices. A survey was performed on Japanese citizens from all parts of Japan to capture the environmental awareness and the SRAS indices. To consider the distinctions that may exist among the Japanese respondents between global and local environmental awareness, the study also obtained data for these two environmental awareness indices.

By investigating the relationships among the global and local environmental awareness indices and the SRAS, the study revealed that all the indices have bidirectional relationships, indicating that scores on the environmental awareness indices increase with the SRAS scores and vice versa. The study also examined if the same effects of the respondents' differences in demographic characteristics, degree of political and social awareness, and attitudes toward donation on the SRAS index can be captured in the environmental awareness indices. When comparing the estimation results of the environmental awareness and the SRAS models, the directions of the impacts of the covariates on the indices were all similar when the effects were statistically significant. For example, females tend to have higher environmental awareness and SRAS scores, and individuals with higher social interests scored higher on both indices. Hence, the study revealed that environmental awareness indices do capture the characteristics of the SRAS model.

Although both environmental awareness and SRAS indices reflect the prosocial reaction of individuals, the former index is based on one question that seizes respondents' awareness while the latter includes questions capturing altruistic actions. Thus, the result of the study showing bidirectional relationships between the indices elucidates that people who recognize the importance of the environmental issue are more likely taking altruistic actions in their ordinary life. This implies that government and environmental groups might be able to motivate people to become more environmentally active by stimulating their awareness toward environmental problems.

Furthermore, compared with the global environmental awareness index model, the local environmental awareness index was more similar to the SRAS model and had a higher average marginal effect on the SRAS. This may be because the items on the SRAS are based on local situations rather than global ones, suggesting that the items on the SRAS need to be revised to incorporate items that can capture altruistic behaviors that go beyond the local community.

In conclusion, the Likert-type environmental awareness index is strongly related to the SRAS and does become a good indicator to predict an individual's altruism level. However, the study indicated that the SRAS was more related to local environmental awareness, implying that the SRAS should be modified to assess altruistic behaviors for people living in all parts of the world.

To ameliorate a global environmental problem such as climate change, everyone living on this planet needs to realize how their activities impact the global environment. To do this, more people need to care about people living in their local area as well as people living elsewhere on the planet. Furthermore, people need to understand that if we become more environmentally responsible, we could help people from all parts of the world. Therefore, increasing the levels of global environmental awareness is critical for mitigating the effects of economic activities on the global environment. As we found that altruism has a positive impact on increasing an individual's environmental awareness levels, more studies need to be done to investigate what factors can induce people to become more altruistic and what indices are useful for evaluating an individual's altruism level.

Funding: This work was supported by JSPS KAKENHI Grant Number 18K12763.

Acknowledgments: I would like to thank the three anonymous reviewers for providing helpful comments to improve and clarify the manuscript.

Conflicts of Interest: The author declares no conflict of interest. 


\section{References}

1. Shafik, N. Economic development and environmental quality: An econometric analysis. Oxf. Econ. Pap. 1994, 46, 757-773. [CrossRef]

2. Perron, G.M.; Cote, P.R.; Duffy, J.F. Improving environmental awareness training in business. J. Clean. Prod. 2006, 14, 551-562. [CrossRef]

3. Gadanne, D.L.; Kennedy, J.; McKeiver, C. An empirical study of environmental awareness and practices in SMEs. J. Bus. Ethics 2008, 84, 45-63. [CrossRef]

4. Xu, X.; Wang, S.; Yu, Y. Consumer's intention to purchase green furniture: Do health consciousness and environmental awareness matter? Sci. Total Environ. 2020, 704, 135275. [CrossRef] [PubMed]

5. Aruga, K.; Wakamatsu, H. Consumer perceptions toward seafood produced near the Fukushima Nuclear Plant. Mar. Resour. Econ. 2018, 33, 373-386. [CrossRef]

6. Neaman, A.; Otto, S.; Vinokur, E. Toward an integrated approach to environmental and prosocial education. Sustainability 2018, 10, 583. [CrossRef]

7. Panda, T.K.; Kumar, A.; Jakhar, S.; Luthra, S.; Garza-Reyes, J.A.; Kazancoglu, I.; Nayaka, S.S. Social and environmental sustainability model on consumers' altruism, green purchase intention, green brand loyalty and evangelism. J. Clean. Prod. 2020, 243, 118575. [CrossRef]

8. Hiramatsu, A.; Kurisu, K.; Hanaki, K. Environmental consciousness in daily activities measured by negative prompts. Sustainability 2016, 8, 24. [CrossRef]

9. Birch, D.; Memery, J.; Kanakarante, M.S. The mindful consumer: Balancing egoistic and altruistic motivations to purchase local food. J. Retail. Consum. Serv. 2018, 40, 221-228. [CrossRef]

10. Yucedag, C.; Kaya, L.G.; Cetin, M. Identifying and assessing environmental awareness of hotel and restaurant employees' attitudes in the Amasra District of Bartin. Environ. Monit. Assess. 2018, 190, 60. [CrossRef]

11. Leins, C.; Austin, S. Top 5 Countries for Green Living. U.S. News \& World Report. Available online: https://www.usnews.com/news/best-countries/slideshows/the-top-5-countries-for-green-living (accessed on 3 September 2020).

12. Kollmuss, A.; Agyeman, J. Mind the gap: Why do people act environmentally and what are the barriers to pro-environmental behavior? Environ. Educ. Res. 2002, 8, 239-260. [CrossRef]

13. Ham, M.; Horvat, M.; Mrcela, D. Insights for Measuring Environmental Awareness. Ekon. Vjesn. 2016, 29, 159-176.

14. Rushton, J.P.; Chrisjohn, R.D.; Fekken, G.C. The altruistic personality and the self-report altruism scale. Pers. Individ. Differ. 1981, 2, 293-302. [CrossRef]

15. Zizzo, D.J. Do Dictator Games Measure Altruism? In Handbook on the Economics of Reciprocity and Social Enterprise; Bruni, T.L., Zamagni, S., Eds.; Edward Elgar: Cheltenham, UK, 2013; pp. 108-111.

16. Powers, T.L.; Hopkins, R.A. Altruism and consumer purchase behavior. J. Int. Consum. Mark. 2006, 19, 107-130. [CrossRef]

17. Oda, R.; Machii, W.; Takagi, S.; Kato, Y.; Takeda, M.; Kiyonari, T.; Fukukawa, Y.; Hiraishi, K. Personality and altruism in daily life. Pers. Individ. Differ. 2014, 56, 206-209. [CrossRef]

18. Guo, Q.; Sun, P.; Cai, M.; Zhang, X.; Song, K. Why are smarter individuals more prosocial? A study on the mediating roles of empathy and moral identity. Intelligence 2019, 75, 1-8. [CrossRef]

19. Aruga, K. Consumer Behavior to Support the Disaster Region and Altruistic Perception. Pap. Environ. Inf. Sci. 2019, 33, 205-210. (In Japanese)

20. Piliavin, J.A.; Charng, H.-W. Altruism: A Review of Recent Theory and Research. Annu. Rev. Sociol. 1990, 16, 27-65. [CrossRef]

21. Oda, R.; Dai, M.; Niwa, Y.; Ihobe, H.; Kiyonari, T.; Takeda, M.; HIraishi, K. Self-Report Altruism Scale Distinguished by the Recipient (SRAS-DR): Validity and reliability. Jpn. J. Psychol. 2013, 84, 28-36. [CrossRef]

22. Zinbarg, R.E.; Revelle, W.; Yovel, I.; Li, W. Cronbach's $\alpha$, Revelle's $\beta$, and McDonald's $\omega H$ : Their relations with each other and two alternative conceptualizations of reliability. Psychometrika 2005, 70, 123-133. [CrossRef]

23. Knight, A.T.; Cowling, R.M.; Difford, M.; Campbell, B.M. Mapping human and social dimensions of conservation opportunity for the scheduling of conservation action on private land. Conserv. Biol. 2010, 24, 1348-1358. [CrossRef] [PubMed]

24. Kiesling, T.; Salas, S.; Matufoglu, K.; Thiel, M. Who cares about dirty beaches? Evaluating environmental awareness and action on coastal litter in Chile. Ocean Coast. Manag. 2017, 137, 82-95. [CrossRef] 
25. Konisky, D.M.; Milyo, J.; Richardson, L.E. Environmental policy attitudes: Issues, geographical scale, and political trust. Soc. Sci. Q. 2008, 89, 1066-1085. [CrossRef]

26. Chou, K.-L. Effects of age, gender, and participation in volunteer activities on the altruistic behavior of Chinese adolescents. J. Genet. Psychol. 1998, 159, 195-201. [CrossRef] [PubMed]

27. Westlake, G.; Coall, D.; Grueter, C.C. Educational attainment is associated with unconditional helping behaviour. Evol. Hum. Sci 2019, 1, e15. [CrossRef]

28. Hoffman, M. Does higher income make you more altruistic? Evidence from the Holocaust. Rev. Econ. Stat. 2011, 93, 876-887. [CrossRef]

29. Piper, G.; Shnepf, S.V. Gender differences in charitable giving in Great Britain. Voluntas 2008, 19, $103-124$. [CrossRef]

30. Branas-Garza, P.; Capraro, V.; Rascon-Ramirez, E. Gender differences in altruism on Mechanical Turk: Expectations and actual behaviour. Econ. Lett. 2018, 170, 19-23. [CrossRef]

31. Altonji, J.G.; Hayashi, F.; Kotlikoff, L.J. Parental altruism and inter vivo transfers: Theory and evidence. J. Polit. Econ. 1997, 105, 1121-1166. [CrossRef]

32. Durin-Gure, P. Happiness and parental altruism in the United States. Appl. Econ. Lett. 2012, 19, 901-904. [CrossRef]

33. Vyrastekova, J.; Huisman, J.; Mosha, I.; Smits, J. Mothers more altruistic than fathers, but only when bearing responsibility alone: Evidence from parental choice experiments in Tanzania. PLoS ONE 2014, 9, e99952. [CrossRef]

34. Batson, C.D.; Powell, A.A. Altruism and prosocial behavior. In Handbook of Psychology: Personality and Social Psychology; Millon, T., Lerner, M.J., Eds.; John Wiley \& Sons Inc.: New York, NY, USA, 2003; Volume 5, pp. 463-484.

35. Zettler, I.; Hilbig, B.E. Attitudes of the selfless: Explaining political orientation with altruism. Pers. Individ. Differ. 2010, 48, 338-342. [CrossRef]

36. Zabkar, V.; Hosta, M. Willingness to act and environmentally conscious consumer behaviour: Can prosocial status perceptions help overcome the gap? Int. J. Consum. Stud. 2013, 37, 257-264. [CrossRef]

37. Gray, S.G.; Raimi, K.T.; Wilson, R.; Arvai, J. Will Millennials save the world? The effect of age and generational differences on environmental concern. J. Environ. Manag. 2019, 242, 393-402. [CrossRef] [PubMed]

38. Charities Aid Foundation (CAF). CAF World Giving Index 2018. Available online: https://www.cafonline. org/docs/default-source/about-us-publications/caf_wgi2018_report_webnopw_2379a_261018.pdf (accessed on 3 September 2020).

39. Fukasawa, E.; Fukasawa, T.; Ogawa, H. Intergovernmental competition for donations: The case of the Furusato Nozei program in Japan. J. Asian Econ. 2020, 67, 101178. [CrossRef]

40. National Institute of Population and Social Security Research (NIPSSR). Latest Demographic Statistics 2018; National Institute of Population and Social Security Research: Tokyo, Japan, 2018.

41. Larson, R.B. Controlling social desirability bias. Int. J. Mark. Res. 2019, 61, 534-547. [CrossRef]

(C) 2020 by the author. Licensee MDPI, Basel, Switzerland. This article is an open access article distributed under the terms and conditions of the Creative Commons Attribution (CC BY) license (http://creativecommons.org/licenses/by/4.0/). 